\title{
Hypertriglyceridemia-Induced Acute Pancreatitis During Pregnancy
}

\author{
Hale GÖKSEVER ÇELIK, ${ }^{a}$ \\ Engin ÇELIK, ${ }^{a}$ \\ Selin DIKMEN, ${ }^{a}$ \\ Alev ATIŞ AYDINª \\ ${ }^{a} \mathrm{C}$ linic of Obstetrics and Gynecology, \\ Kanuni Sultan Süleyman Training and \\ Research Hospital, İstanbul \\ Received: 17.10.2015 \\ Received in revised form: 04.02.2016 \\ Accepted: 17.03.2016 \\ Available online: 10.04.2018 \\ Correspondence: \\ Hale GÖKSEVER ÇELIK \\ Kanuni Sultan Süleyman Training and \\ Research Hospital, \\ Clinic of Obstetrics and Gynecology, \\ İstanbul, TURKEY \\ hgoksever@yahoo.com
}

This case report was presented as a poster abstract, 15. National Perinatology Congress, 1418 October 2015, Muğla, Turkey.

Copyright $(\subset 2018$ by Türkiye Klinikleri

\begin{abstract}
Acute pancreatitis is a sudden inflammation of the pancreas. It is related with severe complications and high mortality despite treatment. One of the most common causes of acute pancreatitis is hypertriglyceridemia (HTG) that is defined as triglyceride levels more than $150 \mathrm{mg} / \mathrm{dl}$. There are effective treatment choices during pregnancy such as dietary restriction of fat, intravenous heparin and insulin and plasmapheresis. We presented a patient with severe HTG induced pancreatitis during pregnancy. She was consulted with hypertension and epigastric pain in the 31st weeks of gestation. After birth, she was treated successfully with heparin, insulin and cessation of oral intake and total parenteral nutrition.
\end{abstract}

Keywords: Pancreatitis; hypertriglyceridemia; pre-eclampsia; pregnancy

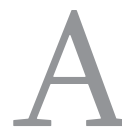
cute pancreatitis is a sudden inflammation of the pancreas. It is related with severe complications and high mortality despite treatment. One of the most common causes of acute pancreatitis is hypertriglyceridemia (HTG). Hypertriglyceridemia is defined as triglyceride levels more than $150 \mathrm{mg} / \mathrm{dl}$. In normal pregnancy, lipid profile can change in response to estrogen levels. But it is important to distinguish normal from abnormal rise. There are effective treatment choices during pregnancy such as dietary restriction of fat, intravenous heparin and insulin and plasmapheresis.

\section{CASE REPORT}

The patient was admitted with epigastric pain, nausea and hypertension in the $31^{\text {st }}$ weeks of gestation. Fetal heart beats were present. On admission, her vital signs were normal except blood pressure which was 150/100 $\mathrm{mmHg}$. She had diabetes mellitus and hepatosplenomegaly in history. Her liver function tests had increased occasionally during pregnancy. Cesarean delivery was performed and a 1375-g female infant was delivered with 1minute Apgar score 7 and 5-minute Apgar score 9. Her laboratory studies showed hematocrit $30.6 \%$ (normal range $35-45 \%$ ), white blood cell count 19.900 cells $/ \mu \mathrm{L}$ (normal range 3700-10.000 cells/L), triglyceride $1108 \mathrm{mg} / \mathrm{dL}$ (normal range $<150 \mathrm{mg} / \mathrm{dL}$ ), amylase $252 \mathrm{U} / \mathrm{L}$ (normal range $<100 \mathrm{U} / \mathrm{L}$ ), lipase $1146 \mathrm{U} / \mathrm{L}$ (normal range <60 U/L), lactate dehydrogenase $3954 \mathrm{U} / \mathrm{L}$ (normal range $<448 \mathrm{U} / \mathrm{L}$ ) and slightly elevated liver and renal function tests. 
Urinalysis showed 2+ proteinuria. So these results was compatible with preeclampsia and suspicious HTG induced acute pancreatitis. We started magnesium sulfate treatment for seizure prophylaxis. During operation, there was accumulation of chylous ascites in abdomen. Also there was a lipemic appearance of blood sample.

Oral intake was stopped and total parenteral nutrition was started with restriction of fat postoperatively. She continued insulin treatment and heparin was started to decrease lipoprotein lipase activity. There was no need for plasmapheresis. Conservative treatment was effective and successful for our patient. The white blood cell count, serum amylase, lipase and triglyceride levels decreased respectively (Figure 1). The patient's clinical condition subsequently improved. On day 15, nutrition with medium chain triglycerides was initiated.

The informed consent had been obtained from the patient.

\section{DISCUSSION}

Acute pancreatitis is a sudden inflammation of the pancreas. Severe complications and high mortality may be encountered despite treatment. The most common causes of acute pancreatitis are alcohol, gall stones, metabolic disorders (hereditary pancreatitis, hypercalcemia, hyperlipidemia, malnutri- tion), abdominal trauma, carcinoma, drug abuse according to the order of frequency. Hypertriglyceridemia is a well-established but underestimated rare cause of acute pancreatitis. Pancreatitis secondary to HTG is typically seen in the presence of one or more secondary factors (uncontrolled diabetes mellitus, alcoholism, medications, pregnancy) in a patient with an underlying common genetic abnormality of lipoprotein metabolism. ${ }^{1}$ Hypertriglyceridemia induced acute pancreatitis is a rare complication in pregnancy but when it occurs, it can result in high fetal and maternal morbidity and mortality.

Hypertriglyceridemia is defined as triglyceride levels more than $150 \mathrm{mg} / \mathrm{dL}$. It can be mild (150-199 mg/dL), moderate (200-999 mg/dL), severe $(1000-1999 \mathrm{mg} / \mathrm{dL})$ or very severe $(>2000$ $\mathrm{mg} / \mathrm{dL}) .{ }^{1}$ There are primary and secondary causes for HTG. Deficiency of lipoprotein lipase or apoprotein C-II leading to chylomicronemia syndrome can be result in primary HTG. Secondary HTG is associated with pregnancy, diabetes mellitus, drug abuse and exogenous estrogen or tamoxifen use. Also chylomicronemia syndrome is obvious clinically when secondary factors (such as pregnancy, diabetes mellitus, etc) exacerbate the underlying abnormality., ${ }^{2,3}$

In normal pregnancy, lipid profile can change due to increased liver synthesis of triglyceride and

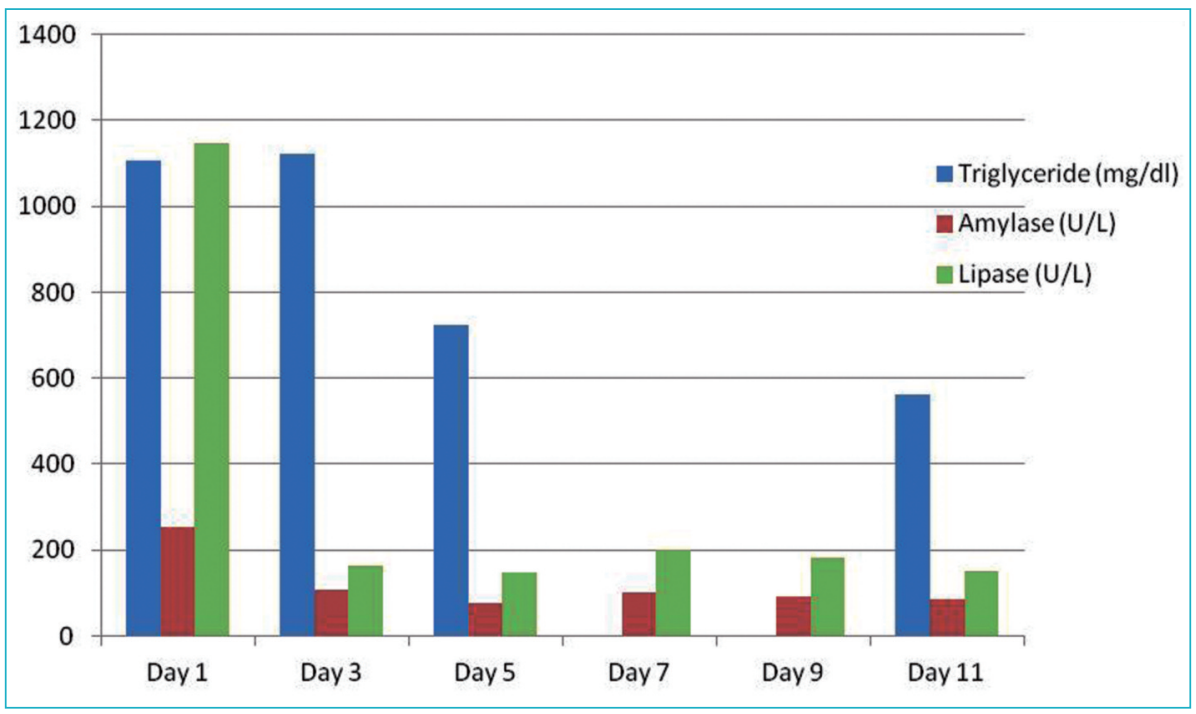

FIGURE 1: Decline in serum triglyceride, amylase and lipase levels during hospital stay. 
very low density lipoprotein-C (VLDL-C) and decreased lipoprotein lipase activity and clearance of VLDL-C in response to estrogen levels. ${ }^{4}$ Total plasma cholesterol and triglyceride levels increase but triglyceride levels rarely exceed $300 \mathrm{mg} / \mathrm{dL}$ by third trimester. If it exceeds, there should be an underlying defect in lipid metabolism.

The most common symptoms of the disease are severe epigastric pain (radiating to the back in $50 \%$ cases), nausea, vomiting, loss of appetite, fever and then hemodynamic instability leading to shock. Previous history of increased lipid profile or family history of lipid abnormality is very important in diagnosis of acute pancreatitis. Severe HTG (serum level of triglyceride $>1000 \mathrm{mg} / \mathrm{dL}$ ) is significant in laboratory tests. Liver function tests (AST, ALT) may increase. Severe HTG include lipemic appearance of blood sample, hepatosplenomegaly and xanthomas over external surfaces of arms, legs and buttocks. Differential diagnosis of labor, perforated peptic ulcus, biliary colic, acute cholecystitis or appendicitis. On that point, symptoms, examination findings and laboratory studies are helpful.

Clinical course and management of acute pancreatitis during pregnancy is similar to that of pancreatitis of other causes. But if there is any risk factor about HTG, the main aim should be prevention of the acute pancreatitis. ${ }^{5}$ Main treatment of HTG induced pancreatitis during pregnancy is dietary restriction of fat, intravenous heparin and insulin together with glucose infusion and lipid-lowering medications. ${ }^{6}$ Insulin and heparin stimulate lipoprotein lipase activity which is functioned as clearence of triglyceride from the plasma. ${ }^{7}$ Also plasmapheresis is an effective alternative to decrease high triglyceride levels and risk of maternal and fetal mortality. ${ }^{8-10}$ Acute pancreatitis itself or associated preeclampsia-eclampsia or HELLP syndrome lead to fetal and maternal death. There is a prediction of maternal mortality as $20 \%$ and fetal mortality as $50 \%$ if HTG induced acute pancreatitis develops. So delivery time is very important that should be individualized to minimize its potential risks. ${ }^{3}$
Our patient was admitted with epigastric pain, nausea and hypertension to our clinics in the 31st weeks of gestation. She had lipid abnormality, diabetes mellitus and hepatosplenomegaly in her history. Pregnancy had induced aggravation of hypertriglyceridemia and associated pancreatitis. Her previous reports showed us mild HTG (triglyceride levels ranging between 200 and $250 \mathrm{mg} / \mathrm{dL}$ ) and occasionally high liver function tests (AST ranging between 70-100 U/L, ALT ranging between 130-150 U/L). We observed chylous ascites in abdomen and milky-pink blood was noticed during cesarean section.

We managed our patient conservatively in postoperative period. We put a drainage catheter into abdomen to prevent accumulation of fatty fluid. Oral intake was stopped and total parenteral nutrition with heparin was started. She continued insulin treatment. The patient's clinical condition subsequently improved.

Hypertriglyceridemia is a known but underestimated cause of acute pancreatitis. Incidence is low but related morbidity and mortality is high. So early diagnosis and good management is the key point for success.

\section{Source of Finance}

During this study, no financial or spiritual support was received neither from any pharmaceutical company that has a direct connection with the research subject, nor from a company that provides or produces medical instruments and materials which may negatively affect the evaluation process of this study.

\section{Conflict of Interest}

No conflicts of interest between the authors and / or family members of the scientific and medical committee members or members of the potential conflicts of interest, counseling, expertise, working conditions, share holding and similar situations in any firm.

\section{Authorship Contributions}

Idea/Concept: Hale Göksever Çelik, Engin Çelik; Design: Hale Göksever Çelik; Control/Supervision: Engin Çelik, Alev Atış Aydın; Data Collection and/or Processing: Hale Göksever Çelik, Selin Dikmen; Analysis and/or Interpretation: Hale Göksever Çelik; Literature Review: Hale Göksever Çelik, Engin Çelik; Writing the Article: Hale Göksever Çelik; Critical Review: Hale Göksever Çelik, Engin Çelik, Alev Atış Aydın; References and Fundings: Selin Dikmen; Materials: Selin Dikmen, Alev Atış Aydın. 


\section{REFERENCES}

1. Scherer J, Singh V, Pitchumoni CS, Yadav D. Issues in hypertriglyceridemic pancreatitis- an update. J Clin Gastroenterol 2014;48(3):195-203.

2. Gürsoy $A$, Kulaksizoglu M, Sahin M, Ertugrul DT, Ozer F, Tutuncu NB, et al. Severe hypertriglyceridemia-induced pancreatitis during pregnancy. J Natl Med Assoc 2006;98(4):655-7.

3. Eskandar O, Eckford S, Roberts TL. Severe, gestational, non-familial, non-genetic hypertriglyceridemia. J Obstet Gynaecol Res 2007;33(2):186-9.

4. Serpytis M, Karosas V, Tamosauskas R, Dementaviciene J, Strupas K, Sileikis A, et al. Hypertriglyceridemia-induced acute pancreatitis in pregnancy. JOP 2012;13(6):677-80.
5. Gupta N, Ahmed S, Shaffer L, Cavens $P$, Blankstein J. Severe hypertriglyceridemia induced pancreatitis in pregnancy. Case Rep Obstet Gynecol 2014;2014: 485493.

6. Nelson-Piercy C, Crook MA. Severe hypertriglyceridemia complicating pregnancy, management by dietary intervention and omega-3 fatty acid supplementation. Nutrition 2009;25 (11-12):1098-9.

7. Sleth JC, Lafforgue E, Servais R, Saizy C, Pluskwa F, Huet D, et al. [A case of hypertriglycideremia-induced pancreatitis in pregnancy: value of heparin]. Ann Fr Anesth Reanim 2004;23(8):835-7.
8. Safi F, Toumeh A, Abuissa Qadan MA, Karaz R, AlAkdar B, Assaly R. Management of familial hypertriglyceridemia-induced pancreatitis during pregnancy with therapeutic plasma exchange: a case report and review of literature. Am J Ther 2014;21(5):e134-6.

9. Niro J, Sapin V, Constantin JM, Cotte B, Lebel $A$, Roszyk L, et al. [Management of gestational hypertriglyceridemia by plasmapheresis]. Gynecol Obstet Fertil 2007;35(11):1133-5.

10. Basar R, Uzum AK, Canbaz B, Dogansen SC Kalayoglu-Besisik S, Altay-Dadin S, et al. Therapeutic apheresis for severe hypertriglyceridemia in pregnancy. Arch Gynecol Obstet 2013;287(5):839-43. 